\title{
Prognostic Significance and Nature of Rhabdoid Features in Renal Cell Carcinoma
}

\author{
Misun Choe · Ji-Young Park \\ Ilseon Hwang · Sang Pyo Kim \\ Department of Pathology, Keimyung University \\ School of Medicine, Daegu, Korea
}

Received: May 4, 2011

Accepted: July 29, 2011

\section{Corresponding Author}

Misun Choe, M.D.

Department of Pathology, Keimyung University

School of Medicine, 194 Dongsan-dong, Jung-gu,

Daegu $700-712$, Korea

Tel: +82-53-580-3815, +82-53-250-7036

Fax: +82-53-250-7211

E-mail: msc@dsmc.or.kr

\begin{abstract}
Background: Recent reports have indicated that renal cell carcinoma (RCC) with rhabdoid features follows an aggressive clinical course. We investigated the prognostic significance and nature of the rhabdoid component. Methods: We retrospectively analyzed the incidence and clinicopathologic characteristics of RCC with rhabdoid features in 174 radical nephrectomy cases. The specimens were examined histologically and immunohistochemically. Results: Twelve of the 174 RCC cases $(6.9 \%)$ showed rhabdoid features. Histologically, all the tumors with rhabdoid features were of the clear cell type. The presence of rhabdoid features was significantly associated with higher Fuhrman's nuclear grade and higher pathologic tumor stage at presentation. Among the 12 patients who showed the rhabdoid component, nine (75\%) developed metastasis and seven (58.3\%) died of disease-related causes. The presence of rhabdoid features was independently associated with metastasis and disease-related mortality. The rhabdoid cells were positive for vimentin; variably positive for pan-cytokeratin, epithelial membrane antigen, and CD10; and negative for cytokeratin 7, smooth muscle actin, desmin, E-cadherin, and c-Kit. No case showed loss of integrase interactor-1; one was p53 positive, and five were insulin-like growth factor mRNA binding protein 3 positive. The Ki-67 labeling index was 1-25\% (mean, 5.5\%). Conclusions: The rhabdoid component is an independent prognostic factor for metastasis of RCC; therefore, identification of this component is critical.
\end{abstract}

Key Words: Carcinoma, renal cell; Kidney; Rhabdoid tumor; Prognosis; Metastasis
Rhabdoid tumor of the kidney is a rare and highly aggressive childhood neoplasm, with a mortality rate of $80 \% .^{1,2}$ This tumor is characterized by rhabdoid cells with large vesicular nuclei, prominent nucleoli, and abundant eosinophilic cytoplasm containing globular inclusion bodies reminiscent of rhabdomyoblasts. Such cells are also encountered in otherwise conventional neoplasms of the kidney ${ }^{1}$ and other organs, which are classified according to the non-rhabdoid, conventional component.

In general, tumors with rhabdoid features are associated with rapid growth and a poor prognosis. Several reports have indicated the significance of rhabdoid features in otherwise typical renal cell carcinoma (RCC), but the independent significance of this component in relation to prognosis has not been thoroughly evaluated. ${ }^{3-6}$ To the best of our knowledge, no study regarding RCC with rhabdoid feature has been reported in Korea. In this retrospective study, we evaluated the incidence and clinicopathologic characteristics of RCC with rhabdoid features to clarify the prognostic significance and nature of the rhabdoid component.

\section{MATERIALS AND METHODS}

\section{Cases and clinical data}

The study included 174 consecutive patients with RCC who underwent a radical nephrectomy at Dongsan Medical Center between January 1997 and December 2007. Clinical data were obtained from the medical records and pathology reports. All RCC histological slides were screened for the presence of rhabdoid cells as described by Weeks et al. ${ }^{1}$ : large epithelioid cells with vesicular nuclei, prominent nucleoli, and large paranuclear intracytoplasmic hyaline globules. Cases with a rhabdoid component comprising roughly $<5 \%$ of the tumor volume were excluded. The tumors were typed histologically according to the 2004 World Health Organization classification and graded according to the Fuhrman's nuclear grading scheme. Further, the pathologic tumor stage was assigned according to the 7 th edition of American Joint Committee on Cancer staging manual. 


\section{Immunohistochemistry}

Paraffin-embedded tissue microarrays were used for immunohistochemistry. A 5-mm-diameter paraffin core was obtained from a representative area of each tumor with the typical rhabdoid feature and arrayed. The following primary antibodies were used: vimentin $(1: 4,000$, mouse, BioGenex, San Ramon, CA, USA), pan-cytokeratin (pan-CK; 1:2,000, mouse, Dako, Glostrup, Denmark), epithelial membrane antigen (EMA; 1:2,000, mouse, Dako), cytokeratin 7 (CK7; 1:2,000, mouse, Dako), smooth muscle actin (SMA; $1: 2,000$, mouse, Dako), desmin (1 :800, mouse, Dako), CD10 (1:100, mouse, Novocastra, Leica Microsystems GmbH, Wetzlar, Germany), E-cadherin (1:1,200, mouse, Zymed, Invitrogen, Carlsbad, CA, USA), c-Kit (1:400, rabbit, Dako), p53 (1:1,000, mouse, Novocastra), insulin-like growth factor mRNA binding protein 3 (IMP3; $1: 300$, mouse, Dako), integrase interactor-1 (INI1) $(1: 200$, mouse, BD, San Jose, CA, USA), and Ki-67 (1:200, mouse, Novocastra).

The immunohistochemical staining procedures were conducted using BenchMark XT with an iVIEW diaminobenzidine (DAB) kit (Ventana Medical Systems Inc., Tucson, AZ, USA) except for IMP3 and INI1, which were immunostained using a Lab Vision Autostainer 360 (Thermo Fisher Scientific, Inc., Fremont, CA, USA) with an Ultravision LP kit (LabVision, Fremont, CA, USA). Briefly, the tissue microarray blocks were cut at $4-\mu \mathrm{m}$ thickness, deparaffinized in xylene, and rehydrated in a graded series of ethyl alcohol. Endogenous peroxidase activity was quenched by immersing the slides in $3 \% \mathrm{H}_{2} \mathrm{O}_{2}$ for 20 minutes. After rehydration with phosphate-buffered saline ( $\mathrm{pH}$ 7.4), microwave-mediated epitope retrieval was performed for vimentin, EMA, SMA, CD10, E-cadherin, c-kit, p53, IMP3, INI1, and Ki-67, but sections for pan-CK and CK7 were incubated in protease. The sections were visualized with $\mathrm{DAB}$ and counterstained with hematoxylin. Appropriate positive and negative control sections were also used.

The Ki-67 labeling index (percentage of Ki-67-positive nuclei) was determined by assessing the area with maximal staining at $\times 400$ magnifications. The remaining results were graded depending on the percentage of positive cells, irrespective of the intensity of the immunoreactive signal, as follows: no positive cells in the rhabdoid component, 0 ; positive cells in $<5 \%$ of the rhabdoid component, 1; positive cells in 5-50\% of the rhabdoid component, 2; positive cells in $>50 \%$ of the rhabdoid component, 3. Cases with grade 0 or 1 were considered negative for expression and those with grades 2 to 3 were defined as positive.

\section{Statistical analysis}

The relationship of the presence of rhabdoid features with patient age and tumor size was analyzed with the independent t-test. Fisher's exact test was used to analyze the relationship between the presence of the rhabdoid component and gender. The relationships with pathologic tumor stage and Fuhrman's nuclear grade were analyzed by the chi-square test with linearby-linear association. After an initial screening for associations with metastasis using a univariate analysis, a multivariate analysis with a logistic regression model was conducted by including the significant variables in the univariate analysis. A Kaplan-Meier analysis and the Cox regression model corrected for competing risks were applied to analyze the significant risk factors for disease-related mortality. All statistical analyses were performed using PASW ver. 18.0 (IBM SPSS Inc., Chicago, IL, USA). A p-value of $<0.05$ was considered statistically significant.

\section{RESULTS}

\section{Clinicopathologic characteristics}

The male-to-female ratio and age of the 174 patients with RCC were 1.9: 1 and 19-82 years (mean, $55 \pm 12$ years), respectively. The tumor size ranged from 1.0 to $17.0 \mathrm{~cm}$ (mean, $5.7 \pm$ $2.8 \mathrm{~cm})$. Histologically, $146(83.9 \%)$ tumors were of the clear cell type; others included papillary, chromophobe, Xp11 translocation, mucinous tubular and spindle cell, and unclassified types. RCCs with rhabdoid features were identified in 12 of the $174(6.9 \%)$ cases (Table 1). All RCCs with rhabdoid features were of the clear cell type, comprising $8.2 \%$ of the 146 clear cell-type cases, and the rhabdoid component constituted 5-90\% of tumor volume. Areas with rhabdoid features were closely associated with clear cell areas with conventional morphology or sarcomatoid changes and were almost always accompanied by necrosis, except in one case. Rhabdoid cells were mostly discohesive and arranged in diffuse sheets as alveolar structures with thin fibrovascular septae or individual cells scattered among conventional tumor cells (Fig. 1). Desmoplasia and a myxoid stroma were observed in two and one case, respectively. Fuhrman's nuclear grade for the rhabdoid component was either $3(\mathrm{n}=2$, $16.6 \%)$ or $4(\mathrm{n}=10,83.3 \%)$. Multinucleated giant cells in rhabdoid foci were observed in 10 of the 12 cases (83.3\%).

Follow-up data were available for all 146 patients with clear 
Table 1. Clinicopathologic summary of renal cell carcinoma cases with rhabdoid features

\begin{tabular}{rcccccccccc}
\hline Case No. & Age $(\mathrm{yr})$ & Sex & Size $(\mathrm{cm})$ & T stage & $\begin{array}{c}\text { Nuclear } \\
\text { grade }\end{array}$ & $\begin{array}{c}\text { Volume } \\
(\%)\end{array}$ & $\begin{array}{c}\text { Sarcomatoid change/ } \\
\text { Necrosis }\end{array}$ & $\begin{array}{c}\text { Ki-67 index } \\
(\%)\end{array}$ & Metastasis & Outcome \\
\hline 1 & 61 & $\mathrm{M}$ & 5.7 & $3 \mathrm{~b}$ & 4 & 30 & $+/+$ & 1 & + & DOD \\
2 & 45 & $\mathrm{M}$ & 7.0 & $1 \mathrm{~b}$ & 4 & 20 & $+/+$ & 1 & + & DOD \\
3 & 45 & $\mathrm{M}$ & 5.3 & $1 \mathrm{~b}$ & 3 & 15 & $-/+$ & 2 & + & DOD \\
4 & 65 & $\mathrm{M}$ & 8.0 & $2 \mathrm{a}$ & 4 & 40 & $-/+$ & 6 & - & NED \\
5 & 55 & $\mathrm{M}$ & 7.0 & $1 \mathrm{~b}$ & 4 & 10 & $-/+$ & 1 & + & AWD \\
6 & 63 & $\mathrm{M}$ & 10.5 & $3 \mathrm{a}$ & 4 & 5 & $-/+$ & 17 & + & DOD \\
7 & 47 & $\mathrm{M}$ & 8 & $3 \mathrm{a}$ & 4 & 40 & $-/+$ & 8 & - & NED \\
8 & 61 & $\mathrm{M}$ & 5.8 & $1 \mathrm{~b}$ & 4 & 8 & $-/-$ & 1 & - & NED \\
9 & 68 & $\mathrm{M}$ & 5.9 & $3 \mathrm{a}$ & 4 & 50 & $-/+$ & 1 & + & AWD \\
10 & 47 & $\mathrm{M}$ & 12.5 & $3 \mathrm{a}$ & 4 & 70 & $-/+$ & 1 & + & DOD \\
11 & 71 & $\mathrm{~F}$ & 6.8 & $3 \mathrm{a}$ & 4 & 60 & $-/+$ & 25 & + & DOD \\
12 & 49 & $\mathrm{M}$ & 11.0 & $3 \mathrm{a}$ & 3 & 90 & $-/+$ & 2 & + & DOD \\
\hline
\end{tabular}

a Volume (\%) indicates the volume of rhabdoid component in the entire renal cell carcinoma.

M, male; DOD, dead of disease; NED, no evidence of disease; AWD, alive with metastatic disease; F, female.
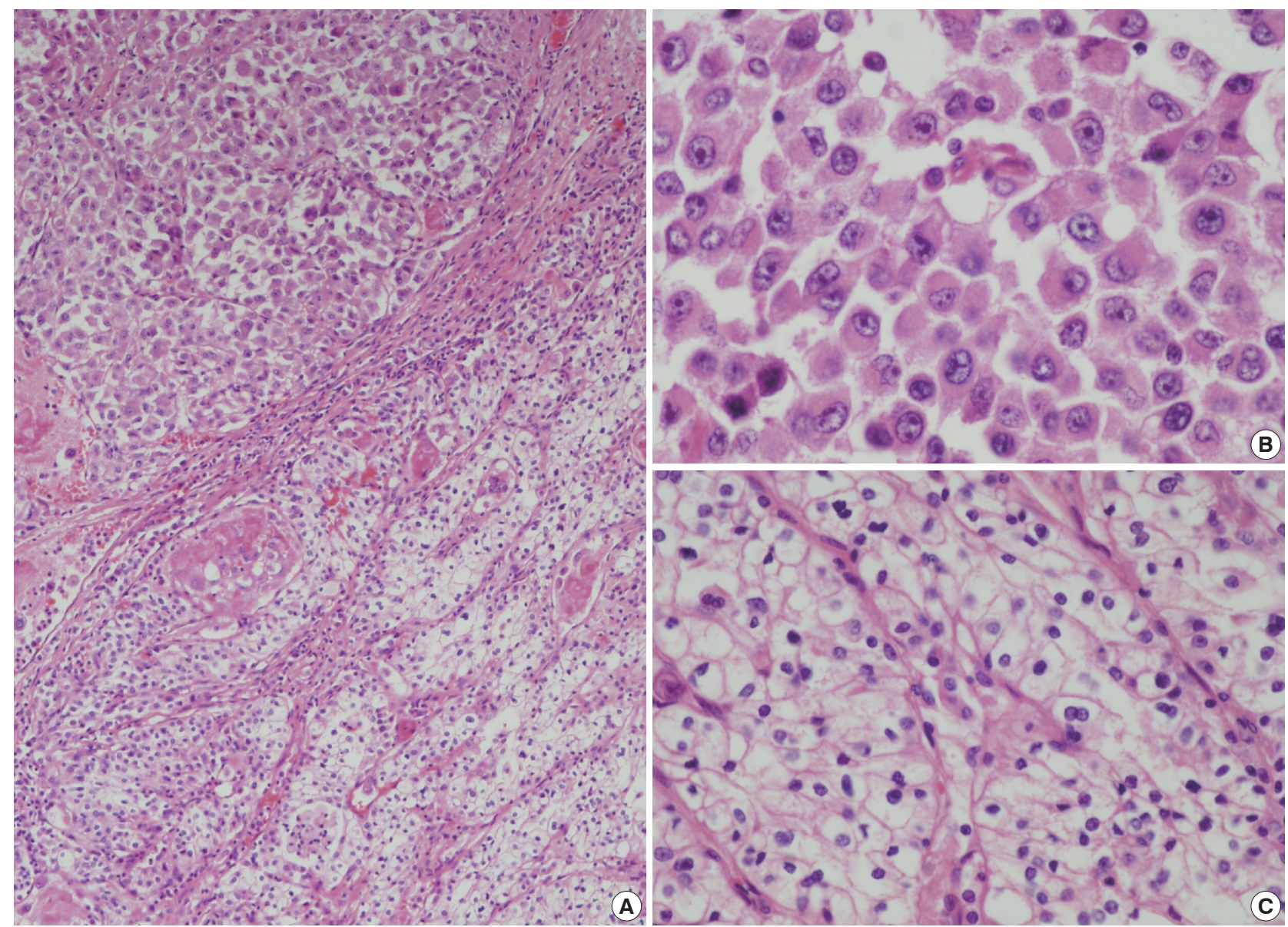

Fig. 1. Radical nephrectomy specimen showing the (A) close association between rhabdoid cells (upper) and clear cells in renal cell carcinoma (lower). (B) The rhabdoid cells exhibit vesicular nuclei, prominent nucleoli, and intracytoplasmic hyaline globules, (C) compared with clear cells.

cell-type RCC (mean duration, $45 \pm 31$ months; median duration, 37 months; range, 1 to 135 months). At presentation or during follow-up, metastasis developed in 29 of the $146(19.9 \%)$ patients, including nine (75\%) with the rhabdoid component. Disease-related death occurred in 21 (14.4\%) of 146 patients, including seven (58.3\%) patients with rhabdoid features. 


\section{Relationship between rhabdoid features and clinicopathologic parameters}

The presence of rhabdoid features was positively correlated with larger tumor size $(\mathrm{p}=0.002)$, higher pathologic tumor stage $(\mathrm{p}=0.001)$, and higher nuclear grade $(\mathrm{p}<0.001)$ of the clear cell-type RCCs. No differences in gender or age distribution were observed between the RCCs with and without rhabdoid features (Table 2).

\section{Univariate and multivariate analyses of the clinicopathologic parameters related to metastasis}

The presence of metastasis showed a significantly strong association with the presence of rhabdoid features $(\mathrm{p}<0.001)$. Metastasis was also significantly associated with higher nuclear grade $(\mathrm{p}<0.001)$ and pathologic tumor stage $(\mathrm{p}<0.001)$ in the univariate analysis but showed no significant correlation with age or gender (Table 3).

In the multivariate analysis, nuclear grade and pathologic tumor stage were each recategorized into two groups (low vs high) (for nuclear grade, 1 and 2 vs 3 and 4; for pathologic tumor stage, 1 and 2 vs 3). After adjusting for the presence of rhab-

Table 2. Relationship between rhabdoid features and clinicopathologic parameters of clear cell-type renal cell carcinoma (RCC)

\begin{tabular}{lccc}
\hline $\begin{array}{l}\text { Clinicpathologic } \\
\text { parameters }\end{array}$ & $\begin{array}{c}\text { RCC without } \\
\text { rhabdoid features }\end{array}$ & $\begin{array}{c}\text { RCC with rhabdoid } \\
\text { features }\end{array}$ & p-value \\
\hline $\begin{array}{l}\text { No. of pateints } \\
\text { Age (yr) }\end{array}$ & 134 & 12 & \\
Male/Female ratio & $56.2 \pm 12(19-82)$ & $56.4 \pm 10(45-71)$ & 0.959 \\
Pathologic tumor stage & $94 / 40$ & $11 / 1$ & 0.18 \\
1a & $54(40.3)$ & $0(0.0)$ & 0.001 \\
$1 \mathrm{~b}$ & $34(25.4)$ & $4(33.3)$ & \\
$2 \mathrm{a}$ & $18(13.4)$ & $1(8.3)$ & \\
$2 \mathrm{~b}$ & $5(3.7)$ & $0(0.0)$ & \\
3a & $23(17.2)$ & $6(50)$ & \\
3b & $0(0.0)$ & $1(8.3)$ & \\
Tumor size (cm) & $5.4 \pm 2.5(1.0-13.8)$ & $7.8 \pm 2.3(5.3-12.5)$ & 0.002 \\
Fuhrman's nuclear grade & & & $<0.001$ \\
1 & $3(2.2)$ & $0(0.0)$ & \\
2 & $35(26.1)$ & $0(0.0)$ & \\
3 & $87(64.9)$ & $2(16.7)$ & \\
4 & $9(6.7)$ & $10(83.3)$ & \\
Metastasis & & & $<0.001$ \\
Absent & $114(85.1)$ & $3(25.0)$ & \\
Present & $20(14.9)$ & $9(75.0)$ & \\
\hline
\end{tabular}

The data represent the mean \pm standard deviation (range) or the number of patients (\%). The bold values indicate a statistically significant difference $(p<$ 0.05 ) by independent t-test (for age and tumor size), chi-square test with linear-by-linear association (for pathologic tumor stage and nuclear grade), and Fisher's exact test (for gender and metastasis). doid features, nuclear grade, and pathologic tumor stage, the multivariate analysis showed that the presence of rhabdoid features $(\mathrm{p}=0.004)$ and pathologic tumor stage $(\mathrm{p}=0.001)$ were significantly associated with metastasis. When the presence of rhabdoid features was used for predicting metastasis, the sensitivity, specificity, positive predictive value, and negative predictive value were $31 \%, 97 \%, 75 \%$, and $85 \%$, respectively.

\section{Correlation between disease-related mortality and rhabdoid features}

In the Kaplan-Meier analysis (Fig. 2), disease-related mortality was correlated with gender $(\mathrm{p}=0.047)$, nuclear grade $(\mathrm{p}<$ $0.001)$, pathologic tumor stage $(\mathrm{p}<0.001)$, and presence of rhabdoid features $(\mathrm{p}<0.001)$.

The multivariate model for disease-related mortality included gender, nuclear grade, pathologic tumor stage, and the presence of rhabdoid features. Nuclear grade and pathologic tumor stage were each recategorized into two groups (low vs high). The outcome was independently associated with the presence of rhabdoid features (hazard ratio [HR], 5.1; 95\% confidence interval [CI], 1.8 to $14.5 ; \mathrm{p}=0.002$ ) and recategorized pathologic

Table 3. Univariate and multivariate analyses of the clinicopathologic parameters of clear cell-type renal cell carcinoma $(\mathrm{RCC})$ related to metastasis

\begin{tabular}{|c|c|c|c|c|c|}
\hline \multirow[b]{2}{*}{ Variable } & \multicolumn{3}{|c|}{ Univariate analysis } & \multicolumn{2}{|c|}{ Multivariate analysis } \\
\hline & $\begin{array}{l}\text { Without } \\
\text { metastasis }\end{array}$ & $\begin{array}{c}\text { With } \\
\text { metastasis }\end{array}$ & $p$-value & $\begin{array}{c}\text { OR } \\
(95 \% \mathrm{Cl})\end{array}$ & $p$-value \\
\hline Age (yr) & $55.3 \pm 11.1$ & $56.0 \pm 14.2$ & 0.06 & & \\
\hline Gender & & & 0.172 & & \\
\hline Female & $36(87.8)$ & $5(12.2)$ & & & \\
\hline Male & $81(77.1)$ & $24(22.9)$ & & & \\
\hline \multicolumn{2}{|c|}{ Pathologic tumor stage } & & $<0.001$ & $5.9(2.2-16.0)$ & 0.001 \\
\hline $1 a$ & $47(87.0)$ & $7(13.0)$ & & & \\
\hline $1 b$ & 34 (89.5) & $4(10.5)$ & & & \\
\hline $2 a$ & 17 (89.5) & $2(10.5)$ & & & \\
\hline $2 b$ & $5(100.0)$ & $0(0.0)$ & & & \\
\hline 3a & $14(48.3)$ & $15(51.7)$ & & & \\
\hline $3 b$ & $0(0.0)$ & $1(100.0)$ & & & \\
\hline \multicolumn{2}{|c|}{ Fuhrman's nuclear grade } & & $<0.001$ & & \\
\hline 1 & $3(100.0)$ & $0(0.0)$ & & & \\
\hline 2 & $34(97.1)$ & $1(2.9)$ & & & \\
\hline 3 & $73(82.0)$ & $16(18.0)$ & & & \\
\hline 4 & $7(36.8)$ & $12(63.2)$ & & & \\
\hline \multicolumn{2}{|c|}{ Rhabdoid features } & & $<0.001$ & $9.0(2.0-40.4)$ & 0.004 \\
\hline Absent & $114(85.1)$ & $20(14.9)$ & & & \\
\hline Present & $3(25.0)$ & $9(75.0)$ & & & \\
\hline
\end{tabular}

Under univariate analysis, the data represent the mean \pm standard deviation or the number of patients (\%). The bold values indicate a statistically significant difference $(p<0.05)$.

$\mathrm{OR}$, odds ratio; $\mathrm{Cl}$, confidence interval. 

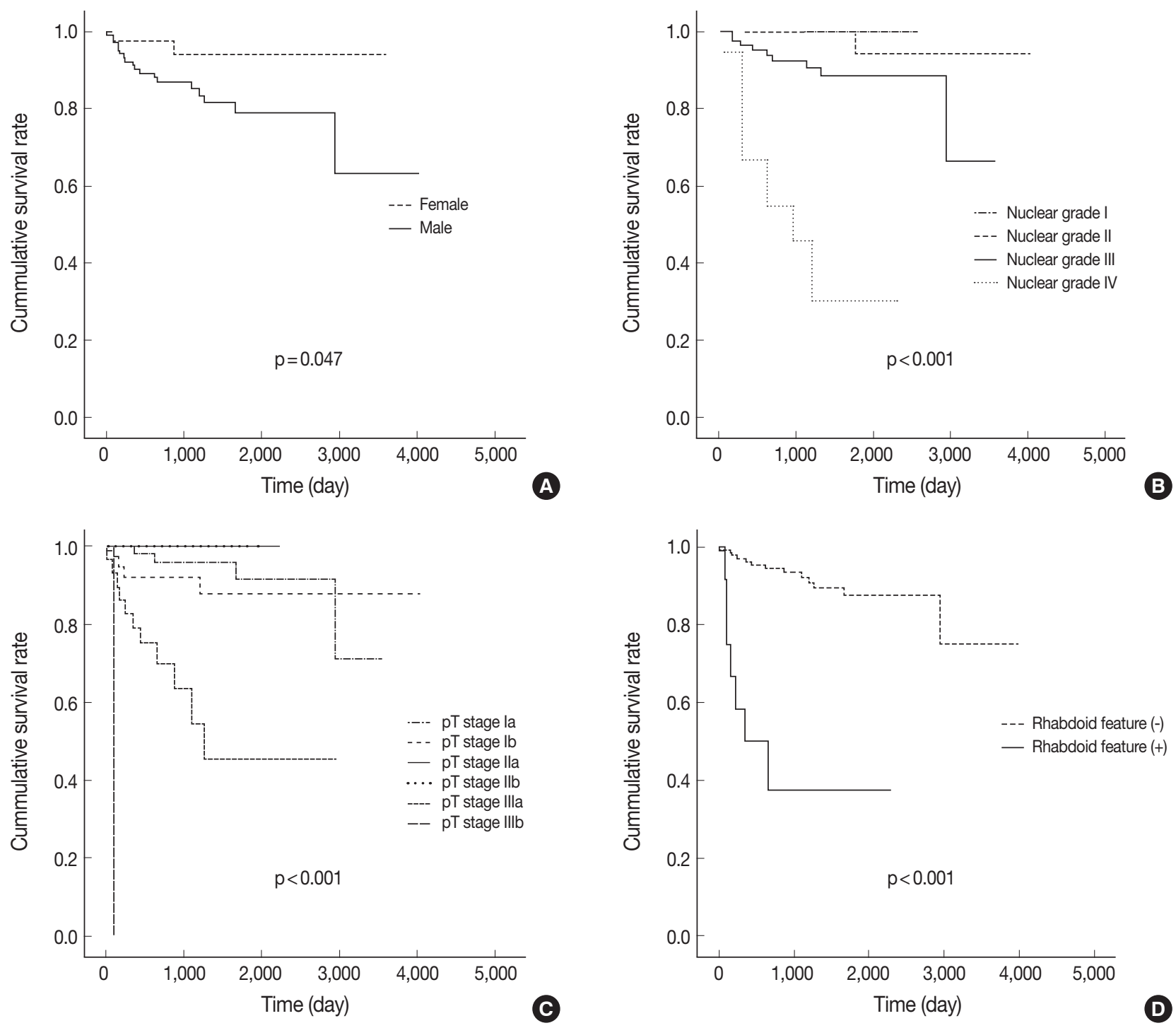

Fig. 2. Kaplan-Meier curves depicting the impact of gender (A), Fuhrman's nuclear grade (B), pT stage (C), and presence of rhabdoid features (D) on the disease-associated mortality of patients $(n=146)$ with clear renal cell carcinoma.

tumor stage (HR, 4.7; $95 \% \mathrm{CI}, 1.9$ to $12.0 ; \mathrm{p}=0.001)$.

\section{Immunohistochemical findings}

The results of the immunohistochemical studies are summarized in Table 4. The rhabdoid component showed diffuse or globular cytoplasmic positivity for vimentin (100\%) in all 12 cases (Fig. 3). No case showed loss of INI1 (0\%). Five were positive for pan-CK ( $42 \%$ ), six were positive for EMA (50\%), and nine were positive for CD10 (75\%). Myogenic markers including SMA and desmin were negative in all cases $(0 \%)$. CK7, Ecadherin, and c-Kit were also negative in all cases $(0 \%)$. p 53 positivity was observed in one (8\%) case, and the Ki-67 labeling index ranged from $<1$ to $25 \%$ (mean, $5.5 \pm 2.3 \%$ ). IMP3 positivity was noted in five $(42 \%)$ cases. IMP3 immunostaining results of the non-rhabdoid areas were available for seven cases, and all of them were positive for IMP3. Interestingly, the rhabdoid areas were negative for IMP3 in three cases with IMP3positive non-rhabdoid areas.

\section{DISCUSSION}

Malignant neoplasms with rhabdoid features have been reported in various organs including the kidney, urinary bladder, and prostate ${ }^{3-6}$ however, the presence of rhabdoid features in 

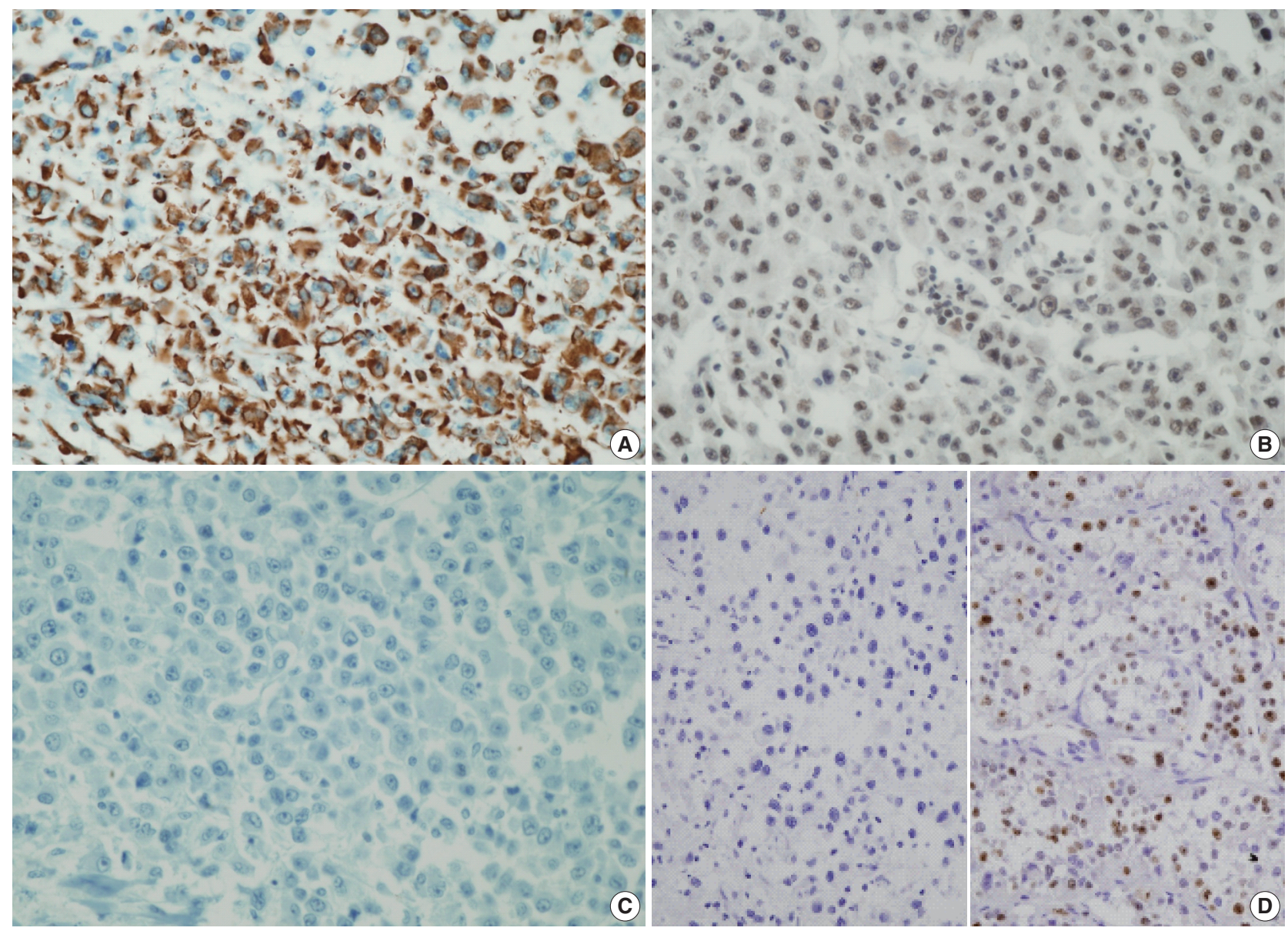

Fig. 3. Specimens showing positive staining for vimentin (A) and integrase interactor-1 (B), and negative staining for p53 (C). The Ki-67 labeling index varied from $1 \%$ (left in D) to $25 \%$ (right in D).

Table 4. Comparison of immunostaining results of rhabdoid cells in renal cell carcinoma between this study and previous studies

\begin{tabular}{lccc}
\hline Staining & Present study & Kuroiwa et al. $^{4}$ & Leroy et al. ${ }^{6}$ \\
\hline Vimentin & $12 / 12(100)$ & $8 / 8(100)$ & $14 / 14(100)$ \\
SMA & $0 / 12(0)$ & $0 / 8(0)$ & $0 / 14(0)$ \\
Desmin & $0 / 12(0)$ & $0 / 8(0)$ & $0 / 14(0)$ \\
EMA & $6 / 12(50)$ & $6 / 8(75)$ & $11 / 14(78)$ \\
Pan-cytokeratin & $5 / 12(42)$ & & $9 / 14(65)$ \\
CK7 & $0 / 12(0)$ & & \\
E-cadherin & $0 / 12(0)$ & & \\
CD10 & $9 / 12(75)$ & & \\
p53 & $1 / 12(8)$ & & $1 / 14(71)$ \\
C-Kit & $0 / 12(0)$ & & \\
IMP3 & $5 / 12(42)$ & & \\
INI1 & $12 / 12(100)$ & & \\
AE1/AE3 & & $6 / 8(75)$ & \\
CAM 5.2 & & $4 / 8(50)$ & \\
HHF-35 & & $0 / 8(0)$ & \\
Chromogranin & & $0 / 8(0)$ & \\
\hline
\end{tabular}

The data represent the positive cases/total cases (\%).

SMA, smooth muscle actin; EMA, epithelial membrane antigen; CK7, cytokeratin 7; IMP3, insulin-like growth factor mRNA binding protein 3; INI1, integrase interactor-1. conventional neoplasms is best characterized in the kidney. Since Gokden et al. ${ }^{3}$ systematically analyzed RCC with rhabdoid features, several reports have emphasized the poor prognosis associated with the rhabdoid component. ${ }^{3-6}$ In neoplasms of other organs such as the stomach, thyroid, meninges, and urinary bladder, ${ }^{7-10}$ the rhabdoid component has also been associated with aggressive behavior. In the kidney, rhabdoid features are predominantly associated with clear cell-type RCCs, but there are reports of associations with papillary- and chromophobetype RCCs, collecting duct carcinoma, renal medullary carcino$\mathrm{ma}$, urothelial carcinoma, synovial sarcoma, and mixed stromal and epithelial tumor. ${ }^{2-6,11-15}$ We found a rhabdoid component in $6.9 \%$ of the 174 cases in this study, which is comparable to the results of previous studies. ${ }^{3-6}$ The reported range of frequency (3.2-7.4\%) may be attributed to the selection criteria; one study with the lowest frequency included tumors with rhabdoid features of more than $10 \%$ only. ${ }^{3-6}$ In our study, the rhabdoid features were associated with clear cell-type RCCs only, and collecting duct carcinoma and renal medullary carcinoma were not in- 
cluded. Their incidence among clear cell-type RCCs was 8.2\%.

When we investigated the prognostic significance of rhabdoid features in RCC, the presence of rhabdoid cells was associated with poor prognostic factors such as a higher nuclear grade, higher pathologic stage, and accompanying tumor necrosis. In the multivariate analysis, the presence of rhabdoid features was one of the independent risk factors for metastasis. Additionally, the presence of rhabdoid features was independently associated with disease-related mortality. Therefore, the presence of a rhabdoid component should receive special attention and should be included in pathologic reports, as in the case of meningioma. ${ }^{8,16}$ Notably, most rhabdoid components were closely associated with necrosis in our study. Leroy et al. ${ }^{6}$ and Kuroiwa et al. ${ }^{4}$ reported areas of necrosis adjacent to the rhabdoid component in 13 of $14(93 \%)$ and all eight cases (100\%), respectively. Therefore, it is advisable to include necrotic tissue during gross examination to obtain additional prognostic information.

The nature and histogenesis of rhabdoid cells in conventional renal neoplasms have not been clearly defined. Rhabdoid cells generally express vimentin and variably express pan-CK and EMA. Myogenic markers are negative. Our immunostaining results are in agreement with these findings. The protein expression patterns somewhat overlap with those seen in rhabdoid tumors, and, therefore, a possibility of a composite tumor consisting of conventional neoplasm and a rhabdoid tumor can be considered. However, the conserved nuclear expression of INI1 in the present study as well as in other studies supports the view that the development of rhabdoid features in conventional neoplasms is unrelated to the histogenesis of rhabdoid tumor. ${ }^{17,18}$ Leroy et al. ${ }^{6}$ reported that $\mathrm{p} 53$ expression is higher in rhabdoid areas than in non-rhabdoid areas, implicating p 53 in tumor dedifferentiation; however, we observed p53 expression in only one case. Miyagi et al. ${ }^{19}$ also reported the lack of p53 expression or mutation in lung adenocarcinoma with rhabdoid features. This contradictory finding in the kidney needs further clarification.

Higher proliferation activity of the rhabdoid component has been reported in the kidney, lung, and meninges. ${ }^{4,16,19}$ Kuroiwa et al. ${ }^{4}$ estimated the proliferation activity of the rhabdoid component as $9.89 \pm 8.35 \%$, which is higher than that of the conventional RCC component. In our study, the Ki-67 labeling index was $5.5 \pm 2.3 \%$, which was not statistically different from the Ki-67 labeling index of the non-rhabdoid component (data not shown). This disagreement may be attributed to the staining fields (whole slide vs microarray) or organ differences and needs further investigation. Our immunostaining results suggest that the development of rhabdoid features is not related to the histogenesis of rhabdoid tumor and may not be associated with a $p 53$ mutation or higher proliferation activity.

Factors other than high proliferation activity may contribute to the aggressive behavior of the rhabdoid component, including loss of cell junctions, cell-cell interactions or cell-extracellular matrix (ECM) interaction, and changes associated with ischemia or necrosis. Most rhabdoid cells are scattered individually and are associated with necrosis. The loss of cell junctions or cell-cell and cell-ECM interaction has been regarded as an important step in the process of tumor metastasis. ${ }^{20,21}$ We did not study the expression patterns of variable adhesion molecules except E-cadherin; thus, this possibility could not be demonstrated. Necrosis in clear cell-type RCC is considered to be a poor prognostic factor, but the underlying mechanisms have not been clarified. ${ }^{22,23}$ IMP3 is an oncofetal protein known to be a good marker for RCC metastasis. ${ }^{24,25}$ Interestingly, the frequency of IMP3 expression in the rhabdoid area was lower than in the nonrhabdoid area.

In the kidney, neoplasms with rhabdoid features should be distinguished from rhabdoid tumors and rhabdomyosarcoma. Rhabdoid tumor, a highly aggressive neoplasm of childhood, is predominantly composed of rhabdoid cells. On ultrastructural study, the characteristic cytoplasmic hyaline inclusion is a whorl of intermediate filaments. This tumor has a molecular hallmark: biallelic inactivation of the bSNF5/INI1 tumor suppressor gene. The loss of INI1 can be demonstrated by immunohistochemical staining ${ }^{18}$ and observed in renal and extrarenal rhabdoid tumors, renomedullary carcinomas, and, variably, in epithelioid sarcomas. Rhabdomyosarcomas are very rarely documented in the kidney. They show characteristic striated muscle differentiation and myoglobin and desmin positivity.

In conclusion, the rhabdoid component of RCC was an independent prognostic factor of metastasis; therefore, its identification is critical. The underlying mechanism of the aggressive behavior needs further investigation.

\section{REFERENCES}

1. Weeks DA, Beckwith JB, Mierau GW, Luckey DW. Rhabdoid tumor of kidney: a report of 111 cases from the National Wilms' Tumor Study Pathology Center. Am J Surg Pathol 1989; 13: 439-58.

2. Weeks DA, Beckwith JB, Mierau GW, Zuppan CW. Renal neoplasms mimicking rhabdoid tumor of kidney: a report from the National Wilms' Tumor Study Pathology Center. Am J Surg Pathol 1991; 15: 1042-54. 
3. Gökden N, Nappi O, Swanson PE, et al. Renal cell carcinoma with rhabdoid features. Am J Surg Pathol 2000; 24: 1329-38.

4. Kuroiwa K, Kinoshita Y, Shiratsuchi H, et al. Renal cell carcinoma with rhabdoid features: an aggressive neoplasm. Histopathology 2002; 41: 538-48.

5. Shannon B, Stan Wisniewski Z, Bentel J, Cohen RJ. Adult rhabdoid renal cell carcinoma. Arch Pathol Lab Med 2002; 126: 1506-10.

6. Leroy X, Zini L, Buob D, Ballereau C, Villers A, Aubert S. Renal cell carcinoma with rhabdoid features: an aggressive neoplasm with overexpression of p53. Arch Pathol Lab Med 2007; 131: 102-6.

7. Ueyama T, Nagai E, Yao T, Tsuneyoshi M. Vimentin-positive gastric carcinomas with rhabdoid features: a clinicopathologic and immunohistochemical study. Am J Surg Pathol 1993; 17: 813-9.

8. Perry A, Scheithauer BW, Stafford SL, Abell-Aleff PC, Meyer FB. "Rhabdoid" meningioma: an aggressive variant. Am J Surg Pathol 1998; 22: 1482-90.

9. Parwani AV, Herawi M, Volmar K, Tsay SH, Epstein JI. Urothelial carcinoma with rhabdoid features: report of 6 cases. Hum Pathol 2006; 37: 168-72.

10. Albores-Saavedra J, Hernandez M, Sanchez-Sosa S, Simpson K, Angeles A, Henson DE. Histologic variants of papillary and follicular carcinomas associated with anaplastic spindle and giant cell carcinomas of the thyroid: an analysis of rhabdoid and thyroglobulin inclusions. Am J Surg Pathol 2007; 31: 729-36.

11. Shannon BA, Cohen RJ. Rhabdoid differentiation of chromophobe renal cell carcinoma. Pathology 2003; 35: 228-30.

12. Kuroda N, Satake H, Miyazaki E, Hayashi Y, Hiroi M, Enzan H. Collecting duct carcinoma exhibiting diastase-resistant PAS-positive globular cytoplasmic inclusions and rhabdoid features arising in adult polycystic kidney disease: a case report. Int J Surg Pathol 2004; 12: $171-7$.

13. Sukov WR, Cheville JC, Lager DJ, Lewin JR, Sebo TJ, Lewin M. Malignant mixed epithelial and stromal tumor of the kidney with rhabdoid features: report of a case including immunohistochemical, molecular genetic studies and comparison to morphologically similar renal tumors. Hum Pathol 2007; 38: 1432-7.

14. Jun SY, Choi J, Kang GH, Park SH, Ayala AG, Ro JY. Synovial sarcoma of the kidney with rhabdoid features: report of three cases. Am J Surg Pathol 2004; 28: 634-7.
15. Cheng JX, Tretiakova M, Gong C, Mandal S, Krausz T, Taxy JB. Renal medullary carcinoma: rhabdoid features and the absence of INI1 expression as markers of aggressive behavior. Mod Pathol 2008; 21: 647-52.

16. Kepes JJ, Moral LA, Wilkinson SB, Abdullah A, Llena JF. Rhabdoid transformation of tumor cells in meningiomas: a histologic indication of increased proliferative activity: report of four cases. Am J Surg Pathol 1998; 22: 231-8.

17. Biegel JA, Kalpana G, Knudsen ES, et al. The role of INI1 and the SWI/SNF complex in the development of rhabdoid tumors: meeting summary from the workshop on childhood atypical teratoid/ rhabdoid tumors. Cancer Res 2002; 62: 323-8.

18. Hoot AC, Russo P, Judkins AR, Perlman EJ, Biegel JA. Immunohistochemical analysis of hSNF5/INI1 distinguishes renal and extrarenal malignant rhabdoid tumors from other pediatric soft tissue tumors. Am J Surg Pathol 2004; 28: 1485-91.

19. Miyagi J, Tsuhako K, Kinjo T, Iwamasa T, Hashimoto H, Ishikawa S. Rhabdoid tumour of the lung is a dedifferentiated phenotype of pulmonary adenocarcinoma. Histopathology 2000; 37: 37-44.

20. Gutwein P, Schramme A, Voss B, et al. Downregulation of junctional adhesion molecule-A is involved in the progression of clear cell renal cell carcinoma. Biochem Biophys Res Commun 2009; 380: 38791.

21. Bissell MJ, Radisky D. Putting tumours in context. Nat Rev Cancer 2001; 1 : 46-54.

22. Lee SE, Byun SS, Oh JK, et al. Significance of macroscopic tumor necrosis as a prognostic indicator for renal cell carcinoma. J Urol 2006; 176(4 Pt 1): 1332-7.

23. Tollefson MK, Thompson RH, Sheinin Y, et al. Ki-67 and coagulative tumor necrosis are independent predictors of poor outcome for patients with clear cell renal cell carcinoma and not surrogates for each other. Cancer 2007; 110: 783-90.

24. Jiang Z, Chu PG, Woda BA, et al. Analysis of RNA-binding protein IMP3 to predict metastasis and prognosis of renal-cell carcinoma: a retrospective study. Lancet Oncol 2006; 7: 556-64.

25. Jiang Z, Chu PG, Woda BA, et al. Combination of quantitative IMP3 and tumor stage: a new system to predict metastasis for patients with localized renal cell carcinomas. Clin Cancer Res 2008; 14: 557984. 